\title{
PROA - Curso de Pós-Graduação Lato Sensu Especialização em Tecnologias da Informação e da Comunicação na Promoção da Aprendizagem
}

\author{
Marcus Vinicius de Azevedo Basso ${ }^{1}$ \\ Rosane Aragon de Nevado ${ }^{1}$ \\ Crediné Silva de Menezes ${ }^{1}$ \\ Iris Elizabeth Tempel Costa \\ Beatriz Corso Magdalena ${ }^{1}$ \\ Léa da Cruz Fagundes ${ }^{1}$ \\ ${ }^{1}$ Curso de Pós-Graduação Lato Sensu Especialização em Tecnologias da Informação e da Comunicação \\ na Promoção da Aprendizagem - Universidade Federal do Rio Grande do Sul. \\ mbasso@ufrgs.br, rosane.aragondufrgs.br, credine@inf.ufes.br, \\ írisetc@gmail.com, beamag@terra.com.br, leafagun@ufrgs.br
}

\begin{abstract}
Resumo
O curso de especialização a distância "Aplicações das Tecnologias da Informação e da Comunicação na Promoção da Aprendizagem", promovido pelo IM/UFRGS, visa qualificar professores para atuarem como multiplicadores do uso das Tecnologias da Informação e da Comunicação na Educação, privilegiando a aprendizagem baseada na construção cooperativa de conhecimento. A arquitetura pedagógica do curso tem por base a utilização de uma metodologia interativa e problematizadora e, como eixo central, o desenvolvimento de "Projetos de Aprendizagem" interdisciplinares com a utilização da telemática. A estruturação básica da formação, enfatiza uma articulação entre os estudos teóricos-metodológicos e a apropriação tecnológica, em torno de situações práticas.
\end{abstract}

Palavras-chave: educação a distância, formação de professores, projetos de aprendizagem

Title: PROA - Lato Sensu Post-Graduation Course of Specialization in Technologies of Information and Communication in the Promotion of Learning

Abstract: The long-distance course "Aplicações das Tecnologias da Informação e da Comunicação na Promoção da Aprendizagem”, accomplished by IM/UFRGS, intend to qualify teachers to act as multipliers of the use of Technologies of Information and Communication in Education, privileging the learning based on cooperative construction of knowledge. The pedagogic architecture of the course has the utilization of an interactive and provocative methodology as basis and has the development of interdisciplinary 'Learning Projects' with the use of digital medias as the central axis. The basic structure of the formation emphasizes an articulation between the theoreticalmethodological studies and the technological appropriation from practical situations.

Keywords: distance learning, formation of teachers, learning projects 


\section{Introdução}

Para atender aos princípios orientadores da política de ação da Administração Central, de produção e disseminação do saber, bem como atender à necessidade de responder ao desafio da inovação, a UFRGS vem implementando diferentes projetos e ações, envolvendo a experimentação e o uso das novas tecnologias da informação e comunicação (TICs).

Dentre esses, destacam-se pelo seu pioneirismo e qualidade acadêmica, os desenvolvidos pela Faculdade de Educação (FACED) e pelo Laboratório de Estudos Cognitivos (LEC) - Instituto de Psicologia. A começar pelo Projeto EDUCOM, iniciado em 1984, a FACED e o LEC têm realizado, sistematicamente, investigações sobre o uso do computador no processo ensino-aprendizagem e desenvolvido atividades de formação de recursos humanos em nível de ensino de graduação, pós-graduação lato e stricto sensu, e de extensão, com vistas a incorporar as novas tecnologias de comunicação e informação - NTCI ao processo educacional.

$\mathrm{O}$ acervo de saberes sobre as possibilidades educativas do uso dessas tecnologias, construído ao longo desse período e orientado numa perspectiva crítica e de construção intersubjetiva do conhecimento, está permitindo propor inovações nos ambientes de aprendizagem bem como desenvolver novos modelos para a formação de professores, tarefa precípua da Universidade.

Em vista do somatório de experiências e resultados dessas duas unidades na formação de recursos humanos, educação a distância, estudo do afeto e da cognição em ambientes informatizados, estudo da cognição de sujeitos portadores de necessidades especiais, robótica, criação de uma cultura de informática, estudo da expressão gráfico-plástica em ambiente informatizado, o Instituto de Matemática (IM) estabeleceu parcerias com as mesmas, no sentido de somar esforços para a implementação de ações para o desenvolvimento de Projetos em Informática na Educação e Educação a Distância. Assim, em um período de mais de dez anos de produção voltada para o ensino e formação de professores, os pesquisadores/docentes do Instituto de Matemática, da Faculdade da Educação e do Laboratório de Estudos Cognitivos, formaram um grupo em torno de um interesse comum: a formação de professores com o uso dos recursos das tecnologias da informação e comunicação. Os doutores em Educação e Informática Educativa do IM têm se identificado e atuado na área de Educação Matemática.

O acúmulo de experiência também tem contribuído para que o Instituto de Matemática, a Faculdade de Educação e o Laboratório de Estudos Cognitivos assumam posição relevante na UFRGS e fora dela, como partícipes privilegiados de projetos educativos oriundos de outras áreas de formação profissional da Universidade e de outros setores ligados à educação, do país e do exterior.

Nessa perspectiva, cabe salientar que a nossa Universidade, através do trabalho do IM, LEC e da FACED, tem sido muito requisitada pelos diferentes governos estaduais, trabalhando sozinha ou em parcerias com as universidades dos Estados em questão, para desenvolver cursos de especialização para formação de multiplicadores, professores da rede pública que passarão a exercer suas funções nos Núcleos de Tecnologia Educacional (NTEs). Esses multiplicadores têm como função formar os professores da rede de escolas parceiras no programa para que possam utilizar, de forma inovadora, os equipamentos recebidos pela escola.

\section{Experiências anteriores}

Estudos, pesquisas e as experiências acumuladas na realização desses Cursos de Especialização e Extensão já estão traduzidos em modelos teórico-explicativos e em modelos metodológicos para orientar as mudanças nas práticas curriculares. 
Em 1986, ministramos o Curso de Especialização para 20 professores de 10 Delegacias Regionais de Ensino da Secretaria de Educação do Estado do Rio Grande do Sul. Em 1988, oferecemos um curso de Especialização em Informática na Educação para professores da Faculdade de Educação da UFPEL (Universidade Federal de Pelotas/RS) para professores da rede estadual e municipal de ensino público.

Os docentes da UFRGS participaram entre 1989/90 dos Cursos de Especialização promovidos pelo PRONINFE/MEC (Programa Nacional de Informática Educativa), dois deles realizados na UNICAMP e um terceiro na Escola Técnica Federal de Goiás. Paralelamente, foi desenvolvida na UFRGS uma sequiência de cursos de extensão, atendendo a demanda de escolas públicas e sistemas municipais de ensino do Rio Grande do Sul.

Entre 1991/92, a partir de pesquisas realizadas para estudar o uso de computadores em rede por alunos surdos, foi desenvolvido o primeiro Curso de Extensão a Distância para Formação de Professores de Educação Especial, visando a introdução da informática em escolas de surdos.

Em 1994, realizamos o primeiro curso de pós-graduação lato sensu - Especialização totalmente a distância usando a Internet e o correio eletrônico. Foram formados e certificados pela UFRGS professores especialistas do Ministério de Educação da Costa Rica, em projeto desenvolvido pela Fundação Omar Dengo (FOD).

Entre 1997/98 realizamos um curso de especialização para professores multiplicadores, numa parceria entre o Estado do Rio Grande do Sul, o ProInfo/SEED/MEC e a UFRGS. Esse curso foi desenvolvido parte a distância e parte presencial. Em 1999, desenvolvemos o II curso de especialização lato sensu "Formação de Professores Multiplicadores para os Núcleos de Tecnologia do Rio Grande do Sul” para formação de um segundo grupo de professores multiplicadores para atuarem nos Núcleos de Tecnologia do RS.

Ainda em 1999, professores do LEC/UFRGS orientaram o planejamento e a execução do curso de especialização de "Formação de Professores Multiplicadores do Vale do Itajaí (SC), em parceria com o Centro Universitário de Jaraguá do Sul”.

Entre 1997-2000 os professores do LEC/UFRGS orientaram o planejamento e a execução de curso semelhante para a formação de professores multiplicadores para os novos Núcleos de Tecnologia Educacional dos Estados de Goiás, Santa Catarina, Piauí e Pará, em parceria com a Universidade Federal de Goiás, Centro Universitário de Jaraguá do Sul, Universidade Federal do Piauí e com a Universidade Estadual do Pará. Em 2000 foi realizado o primeiro curso de pós-graduação lato sensu, nível de aperfeiçoamento, totalmente a distância, usando uma plataforma na Web, para formação continuada de professores especialistas, atendendo, em parceria com o ProInfo/SEED/MEC, os professores multiplicadores de NTEs de todos os estados brasileiros.

Posteriormente, de 2002 a 2004, foram realizados três cursos de especialização, na modalidade a distância: o primeiro deles, de abrangência nacional, e os dois seguintes, respectivamente, para o Estado de Tocantins e estados da Região Norte.

A análise desses resultados permite afirmar que existem condições suficientes para implementação de um curso parcialmente a distância, tendo como metodologia básica o desenvolvimento de projetos interdisciplinares com a utilização da telemática, o que caracteriza o PROA.

Assim, nesse artigo, apresentamos o PROA - Curso de Pós-Graduação Lato Sensu Especialização em Tecnologias da Informação e da Comunicação na Promoção da Aprendizagem, ora em andamento, que dá continuidade às ações realizadas pelo grupo, visando a preparação de novos professores para o uso crítico das novas tecnologias da 
informação e da comunicação, de forma integrada, em suas práticas pedagógicas, assim como para atuarem como multiplicadores do uso dessas tecnologias.

\section{O Curso}

\subsection{Objetivos do Curso}

O PROA, financiado pelo Ministério da Educação - Secretaria de Educação a Distância (SEED/MEC) e com uma carga horária de 405 horas, é destinado para 320 professores que atuam nas redes públicas de educação dos Estados de Santa Catarina, Paraná, Rio Grande do Sul e dos Municípios de Jaraguá do Sul e Florianópolis, ambos de Santa Catarina. A indicação dos cursistas candidato no processo de seleção a uma vaga no curso ficou sob a responsabilidade das respectivas Secretarias de Educação. No processo de seleção, a equipe da UFRGS, responsável pelo curso, levou em consideração a experiência dos candidatos como regentes em escolas, a adesão voluntária ao Curso, a inexistência de registro de evasão em formação anterior do ProInfo/MEC e, como condição fundamental, a de que o cursista possuísse meios para comunicar-se via internet com velocidade e duração diária compatível com as necessidades de um curso a distância.

Os objetivos para a realização do Curso PROA são:

Objetivos Gerais

1. Qualificar professores para capacitar professores das escolas parceiras para a utilização de recursos de interação e comunicação na escola, privilegiando a aprendizagem baseada na construção cooperativa de conhecimento;

2. Criar uma cultura de redes cooperativas intra/inter escolar a partir do uso de novas tecnologias de comunicação e informação na prática pedagógica;

3. Qualificar professores na área de gestão das tecnologias na escola, preparando-os para o trabalho de sensibilização dos gestores escolares.

4. Produzir pesquisas contemplando informática e educação na perspectiva da inclusão digital

5. Produzir pesquisas contemplando informática e educação na perspectiva da capacitação de professores em serviço

6. Desenvolvimento de produtos e ferramentas computacionais de ensino e aprendizagem

Objetivos Específicos

1. Desenvolver modelos de aprendizagem cooperativa que privilegiem o trabalho com projetos interdisciplinares;

2. Vivenciar processos de construção cooperativa de conhecimento favorecido pelo uso de recursos de tecnologias da interação e da comunicação em sala de aula;

3. Refletir sobre aspectos teórico-práticos que propiciem aos professores-alunos, meios adequados para avaliar, criticamente, tanto os métodos educacionais vigentes quanto os recursos de interação e de comunicação disponibilizados;

4. (Re)significar os papéis do professor, enquanto problematizador e orientador dos processos individuais e coletivos de aprendizagem;

5. Utilizar e integrar diferentes mídias em ambientes de aprendizagem construtivista, favorecendo a autonomia, a consolidação de comunidades virtuais de aprendizagem continuada e a incorporação do saber histórico ao mundo vivido;

6. Fornecer subsídios às pesquisas em tecnologias na educação vinculadas a projetos pedagógicos, estimulando, dessa forma, o desenvolvimento da referida área; 
7. Desenvolver estudos e pesquisas sobre questões do uso da tecnologia visando contribuir para a melhoria da qualidade da educação básica priorizando o ensino público;

8. Oferecer subsídios teóricos que propiciem aos professores-alunos, meios adequados para avaliar criticamente tanto os métodos educacionais vigentes quanto os recursos tecnológicos disponibilizados;

9. Realizar pesquisas envolvendo o desenvolvimento e aplicabilidade dos modelos de aprendizagem cooperativa na capacitação de professores em serviço.

Além desses objetivos, o PROA cumpre com importantes funções, tanto no âmbito da UFRGS quanto para o Sistema Educacional Brasileiro:

1. disponibiliza a experiência acumulada de seus pesquisadores e de seus docentes a serviço da Secretaria de Educação a Distância do Ministério da Educação;

2. proporciona, ao quadro de docentes da própria universidade, um contato direto com experiências de educação a distância na formação de professores de redes públicas de ensino fundamental e médio.

Assim, na medida em que presta serviços relevantes ao sistema educacional do país, a UFRGS se beneficia por participar do movimento de criação de Universidades Virtuais.

\subsection{Estrutura do Curso - Projeto Pedagógico}

O curso tem etapas distintas, desde o seu planejamento, até a sua integralização, conforme apresentamos a seguir:

\section{Etapa 1: Preparação do material didático e equipe de trabalho}

A equipe é formada por docentes, tutores (profissionais graduados e com experiência na área de Informática na Educação) e estudantes de graduação que auxiliam no apoio técnico. Essa equipe é responsável pela produção do material didático do Curso.

\section{Etapa 2: Período de Qualificação}

Nessa etapa, foram realizadas atividades que buscaram qualificar os candidatos para a realização do curso:

a) Oficina de instrumentalização (40 horas): oficina de uso dos aplicativos básicos e qualificação no uso do ambiente eproinfo;

b) Fórum temático, com duração de duas semanas, para discussões pedagógicas e produção de texto sintetizando o fórum.

\section{Etapa 3: Desenvolvimento de Oficinas e Seminários}

Nesta nova perspectiva de curso, o design é diferenciado dos moldes tradicionais, não se estruturando em "disciplinas". Sua atividade principal é a realização de um projeto de aprendizagem interdisciplinar, com alunos de escolas públicas (atividade prática), acompanhado do registro no repositório do curso e a análise criteriosa de seu desenvolvimento, fundamentando-o teoricamente. Para subsidiar técnica, metodológica e teoricamente os projetos desenvolvidos de acordo com as necessidades dos alunos, os professores-alunos recebem apoio e orientação dos docentes do curso. Para isso, são desenvolvidas oficinas e seminários. $\mathrm{O}$ conjunto das práticas/discussões/produções/interações, possibilita que os alunos/professores, bem como toda a comunidade participante do curso, vivenciem os benefícios de uma educação autônoma, não hierarquizada e discutam situações de aprendizagem. Nessa perspectiva, os professores-alunos têm possibilidades de se apropriarem de paradigmas educacionais fundamentados numa prática pedagógica construtivista e desenvolverem uma cultura de uso de redes. Para isso, o curso é composto de seminários e oficinas, tendo como eixo os Projetos de Aprendizagem. Cada cursista deverá compor o seu 
currículo com os seminários/oficinas de caráter obrigatório (345 horas) acrescidas de 60 $\mathrm{h}$ de seminários/oficinas de caráter opcional a serem eleitos, entre os apresentados no quadro a seguir:

Seminários: Estudos e debates e produção de conhecimento referente à fundamentação teórica necessária para a inserção da informática nas práticas pedagógicas.

\begin{tabular}{|l|l|c|c|}
\hline \multicolumn{1}{|c|}{ Seminário } & \multicolumn{1}{|c|}{ Caráter } & Modalidade & Horas \\
\hline $\begin{array}{l}\text { Desenvolvimento de Projetos em } \\
\text { Classes de Ensino Básico }\end{array}$ & obrigatório & presencial e EAD & $\begin{array}{c}\text { 20h presenciais + } \\
\text { 60h a distância }\end{array}$ \\
\hline $\begin{array}{l}\text { Análise de Conteúdos Curriculares e } \\
\text { desenvolvimento atividades e EAD } \\
\text { interdisciplinares }\end{array}$ & obrigatório & $\begin{array}{c}\text { 10h presencias + 30h } \\
\text { a distância }\end{array}$ \\
\hline $\begin{array}{l}\text { Metodologias de interação e intervenção } \\
\text { em ambientes informatizados }\end{array}$ & obrigatório & EAD & 30 \\
\hline $\begin{array}{l}\text { Bases Teóricas para Docência em } \\
\text { Ambientes Digitais - ênfase em teorias } \\
\text { de aprendizagem }\end{array}$ & obrigatório \\
\hline $\begin{array}{l}\text { Aplicações da TV Interativa na } \\
\text { aprendizagem }\end{array}$ & obrigatório & EAD & 30 \\
\hline Metodologia da Pesquisa & obrigatório & EAD & 20 \\
\hline Tecnologias na Educação Especial & obrigatório & EAD & 20 \\
\hline Seminário Paulo Freire & opcional & EAD & 20 \\
\hline $\begin{array}{l}\text { Gestão das tecnologias na escola: novos } \\
\text { tempos e espaços }\end{array}$ & opcional & EAD & 20 \\
\hline Seminário de avaliação da aprendizagem & obrigatório & EAD & 30 \\
\hline
\end{tabular}

Oficinas: Nas oficinas é oferecido suporte para o uso de software, ferramentas e serviços de redes. São propostas atividades usando simuladores, robótica, integração de mídias e linguagens de programação.

\begin{tabular}{|l|c|c|c|}
\hline \multicolumn{1}{|c|}{ Oficina } & Caráter & Modalidade & Horas \\
\hline Aplicativos Básicos & obrigatório & presencial e EAD & $\begin{array}{c}\text { 10h presencias + 30h } \\
\text { a distância }\end{array}$ \\
\hline $\begin{array}{l}\text { Ferramentas de interação e comunicação } \\
\text { e integração de mídias (TV, Internet, } \\
\text { rádio) }\end{array}$ & Obrigatório & EAD & 30 \\
\hline Autoria de jogos educacionais & Opcional & EAD & 20 \\
\hline Resolução Cooperativa de problemas & Opcional & EAD & 20 \\
\hline Representação lógica do conhecimento & Opcional & EAD & 20 \\
\hline $\begin{array}{l}\text { Princípios de funcionamento e limites } \\
\text { do computador }\end{array}$ & Opcional & EAD & 20 \\
\hline Uso de Blogs e flogs na educação & Opcional & EAD & 20 \\
\hline
\end{tabular}

\section{Desenvolvimento de Projetos}

Além dos seminários e oficinas sobre metodologia de projetos de aprendizagem é oferecido um espaço de apoio e orientação ao desenvolvimento de projetos quanto aos conteúdos/conceitos relativos às diversas áreas do conhecimento como Matemática, Língua Natural, Geografia, Ciências Sócio-Históricas, Ciências Biológicas, Física, Química e Artes.

\section{Momentos presenciais}

O primeiro momento presencial foi desenvolvido nas cidades de Curitiba, Porto Alegre, Jaraguá do Sul e Florianópolis, atendendo a demanda relativa ao número e local de 
origem dos cursistas. Esse momento inicial foi desenvolvido em 40 horas e constou das seguintes atividades:

- Abertura do Seminário de Projetos

- Abertura da Oficina de aplicativos

- Abertura do Seminário de Conteúdos

Além desse momento presencial, ao final do Curso está prevista a realização de um workshop para apresentação dos trabalhos de finalização do curso.

\section{Seminários e Oficinas}

\begin{tabular}{|c|c|}
\hline Seminário & Súmula \\
\hline $\begin{array}{l}\text { Desenvolvimento de } \\
\text { Projetos em Classes de } \\
\text { Ensino Básico }\end{array}$ & $\begin{array}{l}\text { Conforme descrito na metodologia geral, este curso terá como atividade } \\
\text { principal o desenvolvimento de um projeto de aprendizagem nas escolas } \\
\text { públicas, planejado, desenvolvido e avaliado em colaboração entre o professor- } \\
\text { aluno do curso e professor(es)/aluno(s) de escola pública. Nesse projeto de } \\
\text { aprendizagem estarão integrados os princípios piagetianos e o uso da tecnologia } \\
\text { de informação e comunicação, constituindo-se como base para as discussões e } \\
\text { reflexões teóricas, uso de ferramentas tecnológicas e a produção da } \\
\text { monografia. Na primeira etapa, está prevista a construção de um projeto de } \\
\text { aprendizagem pelos professores alunos do curso, para que vivenciem o processo } \\
\text { pelo qual é construído conhecimento nessa metodologia. Na segunda etapa, os } \\
\text { professores alunos buscarão a parceria de professores de escolas com ambientes } \\
\text { informatizados, para que possam, colaborativa e cooperativamente, desenvolver } \\
\text { a proposta metodológica de aprendizagem por projetos, compreendendo as } \\
\text { relações sócio-cognitivas que se estabelecem num ambiente de aprendizagem e } \\
\text { a construção partilhada e autônoma de conhecimentos. Para atender as } \\
\text { necessidades teóricas, metodológicas e tecnológicas surgidas na prática, os } \\
\text { professores alunos contarão com orientadores e tutores, para auxiliar a teoria e } \\
\text { prática desenvolvida na área de tecnologia na educação. Ao longo do curso será } \\
\text { organizado um repositório de produtos, relatórios de experiências, textos, } \\
\text { webfólios individuais e grupais de avaliação formativa e continuada, como o } \\
\text { registro de suas atividades e coleta de informações. Tais materiais constituirão a } \\
\text { produção do curso. }\end{array}$ \\
\hline $\begin{array}{l}\text { Análise de Conteúdos } \\
\text { Curriculares e } \\
\text { desenvolvimento de } \\
\text { atividades } \\
\text { interdisciplinares }\end{array}$ & $\begin{array}{l}\text { A equipe interdisciplinar do curso oferecerá suporte informacional, tecnológico } \\
\text { e pedagógico durante todo o processo de planejamento, aplicação e discussão de } \\
\text { ações interdisciplinares propostas no ambiente virtual e na sala de aula na } \\
\text { escola. Análise e discussão dos trabalhos realizados pelos alunos, buscando a } \\
\text { identificação dos conteúdos, que neles aparecem e podem ser aprofundados, } \\
\text { com enfoque interdisciplinar. }\end{array}$ \\
\hline $\begin{array}{l}\text { Metodologias de } \\
\text { interação e intervenção } \\
\text { em ambientes } \\
\text { informatizados }\end{array}$ & $\begin{array}{l}\text { Metodologia problematizadora de interação e intervenção em ambientes } \\
\text { informatizados; análise e avaliação das interações sócio-cognitivas e de seus } \\
\text { produtos em ambientes informatizados; levantamento e formulação de } \\
\text { problemas; desenvolvimento de projetos; uso e avaliação de recursos } \\
\text { tecnológicos em trabalhos cooperativos. }\end{array}$ \\
\hline $\begin{array}{l}\text { Bases teóricas para } \\
\text { docência em ambientes } \\
\text { digitais (ênfase em } \\
\text { teorias de } \\
\text { aprendizagem) }\end{array}$ & $\begin{array}{l}\text { Teorias de aprendizagem. A epistemologia genética. Possibilidades de aplicação } \\
\text { das tecnologias da informação e comunicação no apoio à cognição. }\end{array}$ \\
\hline $\begin{array}{l}\text { Aplicações da TV } \\
\text { Interativa na } \\
\text { aprendizagem }\end{array}$ & $\begin{array}{l}\text { Utilização/produção de vídeos para fins pedagógicos. Recursos interativos da } \\
\text { TV Digital. Aplicações pedagógicas dos recursos de interação. Aprendizagem } \\
\text { cooperativa baseada nos recursos da TV interativa. }\end{array}$ \\
\hline $\begin{array}{l}\text { Metodologia da } \\
\text { pesquisa }\end{array}$ & $\begin{array}{l}\text { A construção do conhecimento e o refinamento do pensamento encontram-se na } \\
\text { disponibilidade interior para o debate das próprias convicções, dos conceitos } \\
\text { que cada um elege para pôr em movimento suas pesquisas, do aprofundamento } \\
\text { teórico, da eleição do método como conseqüência de sua pertinência no estudo } \\
\text { e, por fim, da comunicação dessas idéias utilizando recursos que facilitem a }\end{array}$ \\
\hline
\end{tabular}




\begin{tabular}{|l|l|}
\hline & $\begin{array}{l}\text { visualização da sua articulação interna, demonstrando sua propriedade e } \\
\text { coerência. Busca-se o desenvolvimento do espírito de ser pesquisador, capaz de } \\
\text { confrontar constantemente o fazer e o pensar. }\end{array}$ \\
\hline $\begin{array}{l}\text { Gestão das tecnologias } \\
\text { na escola: novos } \\
\text { tempos e espaços }\end{array}$ & $\begin{array}{l}\text { Nesse seminário, será enfocada uma nova visão de gerenciamento da escola, } \\
\text { tendo em vista a introdução das tecnologias da informação e da comunicação. } \\
\text { Nessa abordagem, serão trabalhados e analisados os aspectos relacionados à } \\
\text { importância do papel do gestor frente a inovações decorrentes da incorporação } \\
\text { das tecnologias nas práticas pedagógicas, na organização curricular das } \\
\text { diferentes disciplinas; na questão temporal; na passagem das relações } \\
\text { hierárquicas para relações heterárquicas entre as áreas de conhecimento, grupo } \\
\text { de professores e alunos; na utilização racional e integrada de todos os espaços } \\
\text { da escola e, principalmente, as novas relações que o uso das tecnologias de } \\
\text { comunicação constrói no ambiente escolar. }\end{array}$ \\
\hline Seminário Paulo Freire & $\begin{array}{l}\text { Estudo dos princípios teóricos da pedagogia de Paulo Freire; dimensões da } \\
\text { pedagogia Freireana no espaço virtual; contribuições da Pedagogia Freireana } \\
\text { para o uso da tecnologia na educação. }\end{array}$ \\
\hline $\begin{array}{l}\text { Avaliação da } \\
\text { aprendizagem }\end{array}$ & $\begin{array}{l}\text { Teorias e práticas na avaliação da aprendizagem. Avaliação da aprendizagem } \\
\text { mediada por ambientes virtuais. Avaliação da aprendizagem no } \\
\text { desenvolvimento de projetos. Utilização de webfólios na avaliação. }\end{array}$ \\
\hline $\begin{array}{l}\text { Tecnologias na } \\
\text { Educação Especial }\end{array}$ & $\begin{array}{l}\text { Este seminário tem como objetivo provocar uma reflexão crítica e a construção } \\
\text { de conhecimento a partir da integração das tecnologias na Educação Especial, } \\
\text { buscando dimensionar a ação desta tecnologia no desvelamento de } \\
\text { potencialidades de alunos com necessidades educacionais especiais rumo a uma } \\
\text { sociedade mais inclusiva. Este processo envolverá discussões sobre como as } \\
\text { nossas concepções e crenças sobre as pessoas portadoras de necessidades } \\
\text { especiais determinam nossa prática como educadores. Envolverá, também, } \\
\text { conhecer o que é tecnologia assistiva assim como conhecer experiências } \\
\text { envolvendo PNEEs e as tecnologias. }\end{array}$ \\
\hline
\end{tabular}

\begin{tabular}{|c|c|}
\hline Oficinas & Súmula \\
\hline Aplicativos Básicos & $\begin{array}{l}\text { Utilização de programas essenciais ao uso pedagógico do computador, } \\
\text { considerando o ambiente operacional Linux: sistema operacional; editor de } \\
\text { texto; planilha eletrônica, construtor de páginas. A utilização se fará associada à } \\
\text { uma série de propostas de projetos, que integram o uso dos softwares de forma } \\
\text { interdisciplinar e integrada à proposta pedagógica considerada. }\end{array}$ \\
\hline $\begin{array}{l}\text { Ferramentas de } \\
\text { interação e } \\
\text { comunicação e } \\
\text { integração de mídias } \\
\text { (TV, Internet, rádio) }\end{array}$ & $\begin{array}{l}\text { Suporte à comunicação: a) assíncrona: correio eletrônico, lista de discussão, } \\
\text { fórum e livro de visitas; e b) síncrona: bate-papo e videoconferência. Softwares } \\
\text { para manuseio de vídeos digitais. Software para manuseio de áudios. Análise } \\
\text { dos recursos sob o ponto de vista pedagógico, questionando como podem ser } \\
\text { utilizados no apoio à interação e comunicação. Integração de mídias através da } \\
\text { Internet. }\end{array}$ \\
\hline $\begin{array}{l}\text { Autoria de jogos } \\
\text { educacionais }\end{array}$ & $\begin{array}{l}\text { Representação e simulação de mundos através de jogos. Modelagem de jogos } \\
\text { educacionais interativos baseados na descrição de objetos, eventos e interações. } \\
\text { Ambientes para construção de jogos. Construção de jogos utilizando um } \\
\text { ambiente interativo de desenvolvimento de jogos. Análise e avaliação de jogos } \\
\text { educacionais. }\end{array}$ \\
\hline $\begin{array}{l}\text { Resolução cooperativa } \\
\text { de problemas }\end{array}$ & $\begin{array}{l}\text { O trabalho nessa oficina terá como ponto de partida a introdução de problemas } \\
\text { complexos da vida real, para que os alunos, a partir de processos interativos de } \\
\text { trocas possam chegar a resolvê-los de forma individual e coletiva. } \\
\text { Os professores alunos exercitarão ações investigativas, envolvendo-se, } \\
\text { ativamente, na busca, seleção e análise de dados no seu significado, pertinência } \\
\text { e relevância, no âmbito do que foi proposto e no desenvolvimento de estratégias } \\
\text { de organização e apresentação, que permitam atingir a meta que é a solução do } \\
\text { problema. Nessa oficina trabalharão de forma interdisciplinar diferentes } \\
\text { especialistas para oferecer suporte informacional, tecnológico e pedagógico } \\
\text { durante todo o processo de discussão e resolução dos problemas propostos. }\end{array}$ \\
\hline $\begin{array}{l}\text { Representação lógica } \\
\text { do conhecimento }\end{array}$ & $\begin{array}{l}\text { Introdução à representação formal de conhecimento. Conceitos e relações. Fatos } \\
\text { e regras. Dedução automática. O conceito de variável. Utilização de uma } \\
\text { linguagem de programação baseada em lógica simbólica. Escrita de programas }\end{array}$ \\
\hline
\end{tabular}




\begin{tabular}{|l|l|}
\hline $\begin{array}{l}\text { Princípios de } \\
\text { funcionamento e } \\
\text { limites do computador }\end{array}$ & $\begin{array}{l}\text { para descrição de situações práticas. } \\
\text { procedimentos; computabilidade. }\end{array}$ \\
\hline $\begin{array}{l}\text { Uso pedagógico de } \\
\text { ferramentas interativas }\end{array}$ & $\begin{array}{l}\text { Análise de } \text { software nos seguintes aspectos: conteúdo do software, teoria de } \\
\text { aprendizagem que fundamenta o software, grau de interatividade, } \\
\text { aberto/fechado, tipo de atividades possíveis de serem desenvolvidas e facilidade } \\
\text { de manuseio. Suporte à comunicação assíncrona: correio eletrônico, lista de } \\
\text { discussão, fórum e livro de visitas e síncrona: bate-papo, ICQ e } \\
\text { videoconferência. Análise dos recursos sob o ponto de vista pedagógico, } \\
\text { questionando como podem ser utilizados no apoio à interação e comunicação. }\end{array}$ \\
\hline $\begin{array}{l}\text { Uso de blogs e flogs na } \text { na } \\
\text { educação }\end{array}$ & $\begin{array}{l}\text { O uso de páginas dinâmicas na construção de ambientes informatizados para a } \\
\text { educação; história, descrição, criação, configuração e manutenção de um } \\
\text { weblog; } \text { weblogs e educação; introdução à agregação e distribuição de conteúdo, } \\
\text { protocolos de agregação e seu uso em páginas dinâmicas. }\end{array}$ \\
\hline
\end{tabular}

\subsection{Metodologia}

\section{Metodologia Interativa e Problematizadora}

A metodologia aplicada neste Curso vem sendo desenvolvida e testada desde o primeiro curso a distância que o grupo interdisciplinar de pesquisadores do LEC realizaram em 1994, utilizando a Internet. Neste novo modelo de EAD, tanto os planos de curso, quanto seus relatórios e avaliações vêm sendo submetidos e analisados pela Comissão de Pesquisa da Unidade e pela Câmara de Pós-Graduação do Conselho de Ensino, Pesquisa e Extensão da UFRGS. A partir de 1998, este modelo, baseado no desenvolvimento de Projetos de Aprendizagem, tem sido aprovado também como proposta da Faculdade de Educação desta Universidade e, nesse momento, pelo Instituto de Matemática.

\section{Suporte Tecnológico para as Aplicações da Metodologia na modalidade EAD}

Para apoiar todas as comunicações síncronas e assíncronas, bem como a realização de projetos e demais atividades do curso, está sendo utilizado o ambiente virtual $\boldsymbol{e}$-Proinfo, desenvolvido pela equipe do PROINFO e instalado nos servidores do CETE (Centro de Desenvolvimento Tecnológico do PROINFO). Este ambiente está disponível em http://www.eproinfo.mec.gov.br.

Além do ambiente e-Proinfo também tem sido utilizados blogs e wikis segundo a estrutura representada na figura 1 .

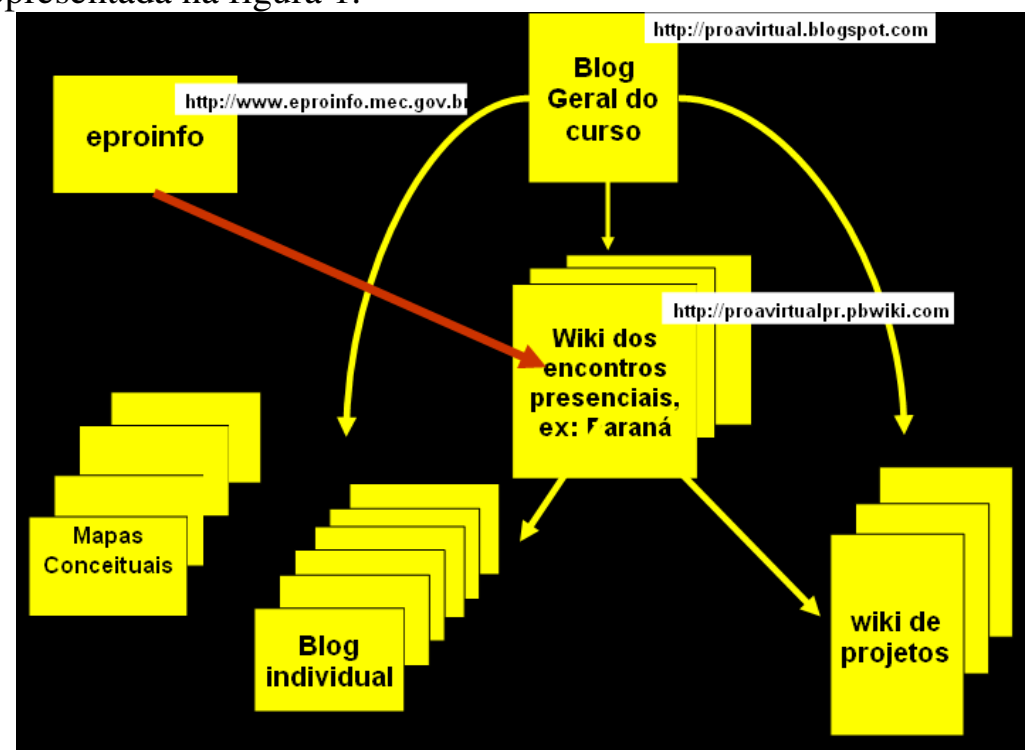

Figura 1 


\section{Funções dos Docentes do Curso}

Os docentes do curso, pesquisadores e professores doutores e/ou mestres da Universidade Federal do Rio Grande do Sul, atuarão em funções diferenciadas, mas complementares, conforme discriminamos a seguir:

a) Especialistas - responsáveis pelos seminários, bem como pelo suporte qualificado aos grupos dentro de seus campos de especialização. Terão a seu cargo auxiliar os professores alunos a estabelecerem relações entre as suas áreas de conhecimento e a exploração qualificada dos ambientes informatizados de aprendizagem (recursos tecnológicos à disposição nos casos específicos de exploração de conteúdos, metodologias de interação, conceitos teóricos fundamentais para construir $e$ sistematizar o conhecimento), de modo que possam depois orientar, nesses ambientes e nas escolas públicas de seus locais de origem, o trabalho docente voltado para mudanças nas práticas curriculares e para a promoção de modelos de aprendizagem cooperativa.

b) Orientadores - responsáveis pela orientação dos grupos no levantamento de problemas de seu interesse; no planejamento, desenvolvimento e avaliação dos projetos partilhados; na elaboração de relatórios diários (das atividades) e finais (dos projetos desenvolvidos) com o apoio dos recursos tecnológicos à disposição. Têm a seu cargo acompanhar o trabalho dos grupos em seus projetos. No projeto desenvolvido com alunos, orientarão os grupos quanto às possibilidades de exploração dos recursos tecnológicos, estratégias de resolução de problemas, sistematização de conteúdos para estabelecer relações produtivas entre as informações das áreas de interesse envolvidas no projeto. Já no trabalho de conclusão, terão a seu cargo acompanhar e orientar os professores alunos com relação a observações e interações a serem efetuadas nas escolas; analisar e avaliar as situações ensino-aprendizagem observadas, com vistas a propor questões relevantes para estudo e/ou discussão com especialistas nos seminários. Os orientadores acompanharão, ainda, o desenvolvimento metodológico da prática, descrição e avaliação dos recursos tecnológicos explorados; as técnicas e estratégias de trabalho desenvolvidas; a descrição, as análises e as interpretações dos resultados; as avaliações dos conteúdos dos projetos trabalhados; e as avaliações dessa modalidade de trabalho para a consecução de modelos interativos e cooperativos de aprendizagem.

c) Tutores - responsáveis pela dinamização geral do curso. Têm a seu cargo estabelecer conexões relevantes e necessárias entre alunos e especialistas nas sucessivas etapas de realização do mesmo, tendo em vista efetivar as condições para a promoção do avanço interativo e integrado do conhecimento a ser construído, bem como o desenvolvimento das competências a serem adquiridas. Farão o acompanhamento e o gerenciamento das ações pedagógicas, o gerenciamento da rede de comunicações (agendamento de trocas via chat, abertura de fóruns de debate, publicação de avisos), bem como das informações em circulação (repositórios, além das demais formas de comunicação e registros).

\subsection{Avaliação}

\subsubsection{Avaliação dos Participantes do Curso \\ 2.4.1.1 Modalidade Presencial}

Serão realizadas sessões presenciais de apresentação dos trabalhos de conclusão de curso, avaliados por banca composta pelos docentes do curso e professores universitários das próprias localidades nas quais acontecerão as apresentações da monografia, anteriormente referendada pelo orientador. As sessões serão filmadas e o vídeo será enviado a UFRGS juntamente com uma cópia impressa da monografia, para a avaliação final pelos docentes da UFRGS. 


\subsubsection{Modalidade a Distância}

Nessa modalidade a avaliação deverá considerar:

1. O projeto desenvolvido na escola, minuciosamente documentado em hipertexto no ambiente, incluindo o relatório de todas as suas ações para o alcance dos seus objetivos (estudos teóricos, realização de atividades teórico-práticas previstas).

2. Uso dos recursos tecnológicos; interações nos diferentes espaços oferecidos pelo ambiente virtual e a elaboração e publicação de relatórios diários e finais do trabalho. A avaliação será sistemática e realizada preventivamente no decorrer de todo o curso.

3. Análise do webfólio contendo processos e produtos relativos a aprendizagem.

4. Estatísticas do ambiente do curso que evidenciam, quantitativamente, a participação, interação e cooperação do professor nos diferentes espaços do ambiente virtual.

\subsubsection{Critérios de Avaliação do Desempenho Acadêmico}

A avaliação da aprendizagem será baseada nos seguintes critérios:

1. Intensidade e da qualidade das trocas realizadas pelo professor-aluno nos diferentes espaços de interação oferecidos pelo curso, tanto para buscar informações quanto para socializar/refletir sobre questões prático-teóricas e responder a desafios propostos por docentes ou outros professores-alunos.

2. Produção do webfólio individual contendo o relato crítico do desenvolvimento do processo de aprendizagem, considerando o processo (re)construtivo a partir da atualização das publicações durante o desenvolvimento do curso.

3. Desenvolvimento do projeto, na escola, com um grupo de alunos.

4. Construção do processo de aprendizagem individual e da atitude de pesquisa individual e coletiva, referenciando-a como princípio educativo.

5. Produção do trabalho de conclusão (TCC).

O TCC consistirá de um estudo empírico de um problema formulado durante o desenvolvimento do projeto de aprendizagem. Os fundamentos teóricos serão apoiados nos estudos realizados no Seminário de Bases Teóricas. O Seminário de Metodologia da Pesquisa oferecerá os subsídios para a formulação do problema e o desenho experimental para a coleta e análise de dados. O Seminário de Interação e Intervenção definirá a contextualização das práticas pedagógicas considerando, tanto a integração das tecnologias e das áreas dos conteúdos curriculares, quanto o processo de elaboração do trabalho de conclusão de curso. O TCC será desenvolvido no formato de hiperdocumento.

\subsubsection{Avaliação do Curso}

Ao finalizar o Curso, com previsão para novembro de 2007, todas as comunicações, discussões e reflexões, relatórios diários e finais estarão disponíveis na Internet e abertos à consulta. Todos esses registros serão dados de pesquisa para o Ministério da Educação, para a Universidade e para as Secretarias de Estado e Municipais da Educação, parceiras nesse processo, para fins de avaliação do modelo de aprendizagem cooperativa proposto para a formação de recursos humanos para a Educação.

\section{Considerações finais:}

O trabalho desenvolvido até o momento tem mostrado algumas necessidades para o alcance dos objetivos de cursos de formação de professores a distância, dentro da perspectiva de construção de conhecimento em comunidades virtuais de aprendizagem. 
As dificuldades enfrentadas levaram a constatações importantes. Dentre elas destacamos a necessidade de:

- disponibilidade de tempo dos professores-alunos para dedicação ao curso. Quando os professores-alunos mantêm todas as suas atividades de trabalho, o andamento do curso é prejudicado, bem como ocorrem desistências em função do estresse causado pelo acúmulo de atividades. Além disso, alguns professoresalunos imaginam que um curso a distância, por não exigir a presença física do aluno numa sala de aula, tem menor exigência quanto ao tempo de dedicação e pode ser realizado com a dedicação de poucas horas nos finais de semana;

- ambientes virtuais estáveis e com equipes de manutenção permanentes. Problemas de instabilidade e demoras na correção de "bugs" ocasionam uma série de desencontros que prejudicam o andamento dos cursos;

- uma sistematização e apresentação clara do uso de diferentes ambientes virtuais, quando esses são utilizados de forma concomitante e possuem funcionalidades semelhantes. Se por um lado, esse uso pode apresentar como conseqüência uma maior fluência digital dos professores-alunos, por outro lado, pode acarretar uma demasiada dispersão nas comunicações e produções;

- interações constantes entre os docentes e tutores mediante uso de ferramentas de interação como lista de discussão, fóruns etc., para que as orientações, discussões e decisões ganhem maior agilidade e coerência;

- formação continuada dos tutores para o acompanhamento dos processos de aprendizagem e uso de metodologias interativas;

- articulação constante entre as propostas de trabalho dos diferentes componentes curriculares para que as atividades sejam abordadas de forma interdisciplinar e ;

- $\quad$ equipes de trabalho dispostas a colaboração/cooperação e a aprendizagem constante;

- romper com a disciplinaridade introduzindo formas de trabalho segundo a metáfora hipertextual de maneira que essas modificações na formação tenham como reflexo mudanças nas práticas pedagógicas dos professores em formação.

Essas constatações têm servido como subsídios para sustentar ações de correções de rotas de trabalho que estão contribuindo tanto para a superação de dificuldades apresentadas pelos professores-alunos quanto na incorporação de novas abordagens para futuras formações de professores em serviço.

\section{Referências}

PIAGET, J. O Possível, o Impossível e o Necessário (As pesquisas em Andamento ou Projetadas no Centro Internacional de Epistemologia Genética). In LEITE, L.B (org). Piaget e a Escola de Genebra.. Cortez Editora. S.P. 1987.

PIAGET, J. Psicologia e Epistemologia. Lisboa: Publicações Dom Quixote, 1991.

BASSO, M.V.A. Espaços de Aprendizagem em Rede: novas orientações na formação de Professores de Matemática. PGIE-UFRGS, 2003.

NEVADO, Rosane; BASSO, Marcus V.; BITTENCOURT, Juliano de V. AMADIS: Ambiente de Aprendizagem a Distância para Formação Continuada de Professores. In: Revista Informática na Educação - Teoria e Prática, vol. 4, $n^{\circ} 2$, PGIEUFRGS, 2001.

NEVADO, Rosane, MAGDALENA, Beatriz e COSTA, Íris. Formação de Professores Multiplicadores: nte2@ projetos.cooperativos.ufrgs.br. In: Revista Informática na Educação - Teoria e Prática, vol. 2 n 2, PGIE-UFRGS, 1999.

FAGUNDES, Léa., MAÇADA, D., Sato, L; Aprendizes do Futuro, as Inovações 
Começaram. MEC, 1999.

FAGUNDES, Léa; NEVADO, Rosane; MENEZES, Crediné; MONTEIRO, Valéria. Ferramenta de Autoria e Interação para apoio ao desenvolvimento de Projetos de Aprendizagem. CINTED-UFRGS, 2005.

NEVADO, R. Espaços interativos de construção de Possíveis: uma nova modalidade de formação de professores. Tese de Doutorado. PGIE/UFRGS. 2001. 